\title{
Technology teacher's perceptions of model functions in technology education
}

\author{
Björn Citrohn ${ }^{1}$ (D) Maria Svensson ${ }^{2}$
}

Accepted: 7 October 2020 / Published online: 13 October 2020

(c) The Author(s) 2020

\begin{abstract}
In this study we investigate how 11 Swedish technology teachers perceive model functions in technology education. The main reason for investigating model functions in technology is an identified lack of knowledge about, and research studies into, a conscious use of models when teaching technology, even though models are part of technology education in many countries. In order to answer the research question of how technology teachers perceive model functions in technology education, we have used directed content analysis where Nia and de Vries (J Technol Des Educ 27:627-653, 2017) model functions constituted a framework. The teachers connect model functions to two teaching contexts: Design process and Explain and facilitate understanding of technological solutions. Model functions are understood as parts of the design process which relate to technology/engineering knowledge, a prescriptive way of understanding models. Models are also used to explain and clarify specific technological situations or functions when teaching technology closely related to a scientific, descriptive way of using models. Five of Nia and de Vries model functions are identified in this empirical study. This strengthens the importance of addressing model functions in technological education.
\end{abstract}

Keywords Model function · Modelling $\cdot$ Technology teacher $\cdot$ Directed content analysis

\section{Introduction}

Technology education today builds on both practical and theoretical knowledge. In many countries the subject of technology has emerged from being a craft-oriented subject towards becoming a more concept-based subject. The change in focus has had an influence on the concepts on which technology education builds today. Modelling in technology is connected to problem-solving, and builds on both practical and theoretical knowledge by

Björn Citrohn

bjorn.citrohn@lnu.se

Maria Svensson

maria.svensson@ped.gu.se

1 Department of Physics and Electrical engineering, Linnaeus University, Växjö, Sweden

2 Department of Pedagogical, Curricular and Professional Studies, University of Gothenburg, Gothenburg, Sweden 
using models as a language for articulating design ideas and suggestions for design solutions. Modelling could be an essential language for communicating design and technological solutions (Roberts, Archer and Baynes 1992). The purpose of the communication differs depending on whether one is the designer, the maker, the user or the observer, but the intention for all is to create a better comprehension of the design and technology activity. Creating and using models for communicating and working with problem-solving is important in the subject of technology, both in primary school and in higher education. Modelling is one of the concepts identified as important for teaching technology in a 2011 Delphi study by approximately 30 experts in technology and engineering education and philosophy of technology (Rossouw, Hacker and De Vries, 2011). The model concept occurs frequently both in the Swedish technology curriculum and in other countries' corresponding curricula (Citrohn 2018). Even if models are recognised as important for understanding technology, there is a lack of literature explaining and discussing the use of, and intentions with, models in compulsory technology education.

A model can be understood as an image or representation of a complex phenomenon. A common feature is that it is often simplified compared to the phenomenon it represents, and only highlights certain aspects or parts of the phenomenon (Allwood 1989). Roberts et al. (1992) stress that models are very powerful to use because of their ability to isolate an aspect of reality. That aspect can be represented, interpreted, controlled and manipulated in the model. Models are used with a descriptive purpose to understand and explain reality, or with a prescriptive purpose used to model a desired reality. Allwood (1989) suggests that models can be divided into three types; Iconic models that try to resemble the thing being modelled, Indexical models that have a causal relation to the thing being modelled, and Symbolic models that try to describe the thing being modelled. The most common models are a combination of Iconic and Symbolic models.

Using models in science and technology education is important for students to understand complex relationships and phenomena, as well as for students' ability to solve problems. The results by Wells et al. (1995) indicate that model-based learning of physics, in high school, significantly increased students' understanding of the content of the course. In a study by Nia and de Vries (2017) they analysed how models are described in US and New Zealand standards for technological literacy. They found that the standards put forward the need for students to be acquainted with different functions of models in order to understand the meaning of models in technology. Nia and de Vries propose a framework that describes the dual nature of models, the intrinsic and the internal. This framework could be a support in understanding how models could be used, or be better used, in technology education, which could benefit both teachers and students. The way in which the use of models is expressed in the curricula (explicit or implicit) of Sweden, Ireland, New Zealand and South Africa has been compared in a study by Citrohn (2018). The Swedish curricula were found to be more implicit regarding the use and descriptions of models than those of the three other countries.

In summary, models in technology are important for understanding and communicating, but also in the design activity, when working with problem-solving (de Vries 2005). The design activity resulting in a product or a system, called the design process, is central in many countries' curricula and in engineering, an area with strong connections to technology. In the design process, model functions are prescriptive: the model is manipulated to create a desired product or reality. The Swedish technology curricula are implicit regarding models and their use, and there is also a lack of literature explaining and discussing the use of models. In order to develop knowledge about the use of models in technology, students and pupils need to understand the specific functions of models. This indicates the 
importance of bringing the functions to the foreground in the teaching, to make students and pupils aware of them. The teacher's own knowledge and awareness about model functions in technology is essential for this. In this study we want to know more about teachers' understanding and use of models in technology education, with the overall research question of how technology teachers perceive model functions in technology education.

\section{Background}

In Sweden, technology is a school subject standing on its own, but the subject has a history of being integrated with science and slöjd (handcraft). Recently there has been a strong trend in many countries towards integrating science, technology, engineering and mathematics education. This is commonly described by the acronym STEM. In relation to these intentions of integrating technology in and with other subjects, it is important to position technology as an independent subject. There are connections between technology, engineering, science and mathematics, but when looking at concepts used in all four areas, there are also important differences. Indeed, models and modelling are used in all four subjects, and can be seen as a bridge between the STEM subjects (Hallström and Schönborn 2019). However, the different uses of models and modelling could also be employed to position the different subjects. In this section we will examine and compare the use of models in science, technology, engineering and mathematics. From a Swedish context, we find it difficult to separate technology and engineering when talking about education in compulsory schools, therefore we describe the use of models in these two areas together. Technology is a subject in Swedish compulsory school with the aim of developing pupils' understanding of the traditions of what knowledge is in our technological culture, and the objective that pupils develop an ability to reflect on, criticise and evaluate the consequences of how technology impacts people, society and nature. If pupils are allowed to investigate, test and develop technological solutions, they will become familiar with the technology that permeates their everyday world. The ultimate purpose is to educate technically literate citizens. Engineering is a knowledge area where the aim is to solve technological problems using a design-based approach that includes knowledge from different areas such as science and mathematics (Mitcham 1994). The purpose of engineering education is to develop specialist knowledge in technology.

Artefact design is what constitutes the essence of engineering, because it is design that establishes and orders the unique engineering framework that integrates other elements. The term technology is largely reserved by engineers for more direct involvement with material construction and the manipulation of artefacts. (Mitcham 1994 p. 147)

However, we will start with a general discussion of how models may be perceived, and the way we connect the study to such general understanding.

\section{Learning framework about models}

Models are often described as cognitive models and expressed models (see e.g. Buckley 2000; Gilbert 2004). This separation, into cognitive and expressed models, has a potential when analysing and describing models, but the two types of model often exist as intertwined and dependent on each other. The cognitive models are internal cognitive 
representations used to generate external representations for reasoning (Buckley 2000). Cognitive models can be influenced by expressed models (e.g. representations), phenomena and information. During model formation, the learner uses existing knowledge and new information to construct cognitive models. When a cognitive model is successfully used to solve the problem, the cognitive model is reinforced, but if the model does not meet the demands of the problem, the model is rejected or revised: see Fig. 1 (Buckley 2000).

\section{Models and modelling and the design process}

As described above, models and modelling are used in science, technology/engineering and maths, and in the three areas they can be used in different ways with different purposes. In science and mathematics, models and modelling are mostly used descriptively, while in technology and engineering, models are also used prescriptively. In order to define and explain our definitions of models, modelling, and the design process, we use an example from technology/engineering:

When constructing a full-sized aeroplane, a scale model of the plane can, apart from understanding and communicating, be used to test certain aspects of the construction. For example, the model can be used to test the plane's aerodynamics in a wind tunnel. The testing might lead to modifications in the model in order to optimise wind resistance. In this example, when the model (the scale model of the aeroplane) is tested, submitted to changes and possibly tested again, we define this work process as modelling. The whole process of designing the aeroplane, from sketch to drawing to the use of model and finally to finished full-scale aeroplane, is defined as the design process.

De Vries (2005) argues that all design processes have three phases in common: analysis, synthesis and evaluation. In the phase of analysis, the problem is analysed and this results in a list of requirements, hence goals/purposes of the artefact. The phase of synthesis results in a solution for the design problem being proposed, and in the evaluation phase the chosen solution is evaluated against the list of requirements. In the Swedish curricula, identification of needs and investigating is related to the analysis phase, while proposing solutions and designing is related to synthesis, and finally testing is related to evaluation.

\section{Models and modelling in the STEM disciplines}

The STEM subject areas represent different types of knowledge (Hallström and Schönborn, 2019). Science studies nature so as to determine laws, Technology and Engineering solve problems with technological solutions and Mathematics assists the other subject areas by

Fig. 1 Learning about models (figure from Buckley 2000, p. 896)

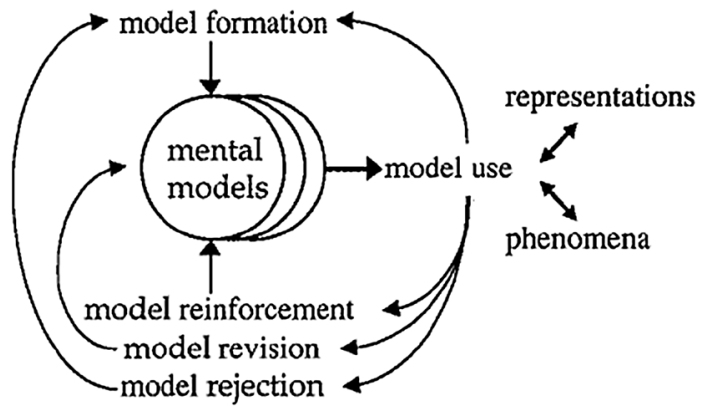


formulating functions that may be used for analysis. When models are used in technology the purpose is to intervene in the world, solve problems and create solutions, while in science the purpose is to understand and explain phenomena in the world (France, Compton and Gilbert 2011); one could say that technology (and also engineering) is normative, and science is descriptive. In all STEM subject areas, the use of models and modelling is included to support understanding. Next, we will describe models and the use of them within the four different subject areas of STEM, starting with mathematics.

\section{Models in mathematics}

The process of developing a mathematical model usually starts with observations and measurements of a given case. The aim is to have a model, which is a relatively simple mathematical function of the case. The steps in the process are; (1) presenting the problem as simply as possible, (2) using modelling concepts to derive various models, (3) evaluating the models to find the optimal one, and (4) demonstrating the advantage of the model by testing it.

The purpose of finding the function is to obtain qualitative and quantitative understanding of the observations (Heinz, 2011). Marion and Lawson (2008) state that models describe our beliefs about how the world functions. In mathematical modelling, we translate those beliefs into the language of mathematics (p. 1). The authors argue that mathematical modelling consists of a large element of compromise but can achieve development of scientific understanding and test systems, and be used as an aid for decision-making. One way of categorising different mathematical models is to look at the outcome they predict, or at the level of understanding on which the model is based.

\section{Models in science}

Models in science are central to knowledge building which rests on the epistemological criterion of scientific knowledge — that is, truth (France et. al 2011, p. 384 ).

In science, models are used to describe and explain phenomena; scientific knowledge is about explaining empirical evidence (France et. al 2011). One can say that a model in science is often a simplified representation of reality. Models can also be an idealisation of a possible reality, based on the abstractions of the theory such as, for example, point-masses or a friction-free world. They can be used to make abstract entities visible, provide descriptions and/or simplifications of complex phenomena and form the basis of both scientific explanations and predictions about phenomena. Model functions are viewed as a bridge between theory and the world as experienced (Gilbert 2004). Seven different functions of models in science are described by Lin (2014) referring to Leatherdale (1974): (1) simplifying complex phenomena; (2) providing methods of understanding theory; (3) providing a prediction function; (4) strengthening prediction function for theory; (5) providing development function for theory; (6) providing media that deepens understanding and broadens our image of theory; and (7) providing a relationship between theory and experiment. An important skill in science for pupils is the modelling ability such as making copies of reality, communicating through models and using models as a tool for developing and testing complex theoretical models (Grosslight, Unger, Jay and Smith 1991). 


\section{Models in technology and/or engineering}

Modelling in technology is central to achieving a technological outcome that fulfils the epistemological criterion of technological knowledge that is successful function. (France et.al 2011. p. 384).

Regarding models in technology, an important aspect, highlighted in research (see e.g. Rossouw et al. 2011; de Vries 2005), is what distinguishes technical artefacts from natural objects. The former is influenced by humans, while the latter is influenced by nature. In technology, the outcomes are artefacts or systems that can be evaluated in relation to their "fit for purpose" and models are often used to enable evaluation of the solution in relation to the purpose (Compton and France 2007). In engineering, technological problems are solved and solutions are designed using knowledge from different fields, such as science, technology and mathematics. Engineering is a decision-making process. When solving technological problems there are often several objectives and criteria that determine whether or not the solution is appropriate (Kroes 2009). According to Simon (1996) the adaptation of an artefact to reach the goal or purpose relates to three terms: the goal/purpose itself, the character of the artefact and finally the environment in which the artefact exists. Models in engineering are used as part of the engineering design to make decisions. Models are used to try out different ways of solving the problem, and the models are also used as representations that can be modified and developed to help the engineer in the decision-making process. A fundamental difference between science and technology/engineering lies in the purpose of the disciplines. The purpose of technology/engineering is to intervene and create solutions, while the purpose of science is to understand the world. The different purposes have implications for the practice of technology/engineering and science (France et.al 2011). In science the outcomes are explanations, whereas in technology/engineering they are artefacts or systems (Simon 1996). The outcome, artefacts and/or systems relate to and carry the technological knowledge, and are validated by the materiality of the outcome itself (France et. al 2011). Students need to be acquainted with different functions of models in order to understand the meaning of models in the subject of technology (Nia and de Vries 2017). In their study, the authors identified eight different functions important for understanding models: demonstrating, designing, testing and (re)evaluating, prototyping, simulating, problem solving, communicating and finally learning. The students also had to be acquainted with different types of models: physical, mathematical, graphical, conceptual and also 2-or 3-dimensional forms.

\section{Models as techno-scientific products}

A way of defining models in science and technology is as techno-scientific products, described as having an intrinsic nature and/or an intentional nature (Nia and de Vries, 2017). These two natures of models can facilitate both science and technology knowledge, depending on how the model is made and what purpose it has. The intrinsic nature of models relates to the material structure such as the material properties, size, weight, colour and number of components. The intentional nature of models is divided into two different parts; one that supports the development of knowledge and artefacts, and another that supports communication about knowledge and artefacts. The first may be used as a tool for examining, understanding and explaining scientific or technological knowledge, or as a tool for building and manipulating in order to understand and learn about design and scientific reasoning. The intentional nature of models that support communication about knowledge 
and artefacts concerns establishing common understanding by distributing information to decision makers, engineers and students.

Research exists concerning models and modelling in the STEM subjects; however, there is a lack of research in relation to teaching. To better understand teaching of models in technology, we wish to investigate technology teachers' perceptions of model functions in technology education.

\section{Methodology}

To answer the question: How do technology teachers perceive model functions in technology education? An appropriate way of investigating this is to use a qualitative method that gives us the opportunity to conduct in-depth interviews with teachers about models. We have analysed the transcribed interviews using a content approach. The content approach is a qualitative analytical method that is flexible and can provide rich and detailed data. The purpose of qualitative content analysis is to analyse text data. Research using qualitative content analysis (Hsieh and Shannon, 2005) focuses on the content or contextual meaning of the text from different sources, such as transcribed interviews. There are different ways of doing the content analysis, described by Hsieh and Shannon (2005). A conventional content analysis is generally used with a study design whose aim is to describe a phenomenon, in this study the technology teacher's perception of models in technology education. In the analysis the researcher allows the categories and names for categories to appear from the data, an inductive category development. A directed content analysis, on the other hand, has a deductive category application. The goal of a directed content analysis is to validate or extend conceptually a theoretical framework or theory, in this study the model functions described by Nia and de Vries (2017).

This study started with the intention to investigate technology teachers' perceptions of models in technology education through a conventional content analysis which, as Elo, Kääriäinen, Kanste, Pölkki, Utriainen and Kyngäs (2014) describe, included open coding, creation of categories and abstraction. This step in analysis resulted in two themes, emphasising models as tools in technology education. However, after a seminar with several experienced researchers, we realised that by using Nia and de Vries' (2017) investigation of policy documents (Standards of technological literacy, STL in USA) with a number of model functions, new possibilities for the analysis were opened with a focus on the functions of models instead of models as a tool. Therefore, as a next step a directed content analysis was conducted, to investigate teachers' perceptions of model functions. The context for Nia and de Vries functions originates from STL in the USA; even though the context differs from the one in Sweden, there are similarities regarding education for technological literacy (Skolverket 2018). The great difference is that data in Nia and de Vries' study derive from policy documents for K12 students (aged 17-18), while our study is an empirical investigation with teachers in technology Grade 7-9 students (aged 13-16). Despite this difference we believe that an empirical study is valuable in order to develop the validity of the model functions for technology teaching.

\section{The interviews}

The process started with creating semi-structured interview questions to learn more about teachers' perceptions of models. The approach was inductive and the questions were tested 
through a pilot interview with an experienced teacher. The pilot interview was transcribed and evaluated and, after some minor adjustments of the interview questions, an interview guide was formulated to support the interviews with the teachers in this study. The questions originated from six different areas, inductively produced with the Swedish technology curricula as a foundation, in which models could be used: models in everyday living and in school, models in the subject of technology, the concept of models and different types of models, model functions, models in the design process, and the learning of pupils when working with models. In order to understand how teachers perceive models, questions were asked in relation to each of these areas. Examples of questions in the area of model functions were: For what, and in what way, do you think you could use models in technology education? Describe how you have used them in these ways. What do you think is important for students to learn when working with models? What difference do you think there is in how you and the students use models in technology, compared to other subjects? These questions were followed by open-ended questions, e.g. Can you tell me more about that? or What do you mean by...? w with the purpose of making the teachers develop the way they perceive models. This method of working with open-ended questions and "probes" that are also open-ended, described by Hsieh and Shannon (2005), is appropriate when exercising theory or if prior research is limited.

\section{The interviewed teachers}

The data was collected through interviews with 11 technology teachers (referred to as T1-T11—see Table 1). The teachers all had a certificate in teaching technology and were experienced (more than 10 years) technology teachers. They were spread geographically from the north to the south of Sweden and were active as technology teachers at the time of the interview. With regard to age and experience, the group of teachers is rather homogenic, which reflects the difficulties in finding teachers to interview. Besides teaching technology, most of them had a combination that included mathematics and physics; one of the teachers had a combination with art. Two of the teachers had both a teaching and an engineering degree.

\section{The analysis of data}

The interviews, all in Swedish, were performed and audio-recorded via ZOOM, an internet-based video conference system, by the first author. The audio-recordings were transferred into MAXQDA 2018 (VERBI Software 2019), a program for data analysis, and the interviews were transcribed verbatim in Swedish. The transcripts were read thoroughly to find patterns linked to the teacher's understanding and use of models, with conventional content analysis as a guiding principle. Tentative patterns were identified and described as themes with their own categories. After discussing the preliminary identified themes with research colleagues, so as to obtain a broader perspective of the interpretations, the transcripts were revisited and the themes were reviewed.

The conventional content analysis resulted in two themes: models as a tool for communication and models as a tool for the design process. These two themes gave us an indication as to how the teachers understood models in technology education. However, as described above we saw new possibilities using a directed content analysis. The aim of doing such an analysis was to receive a deeper understanding of teachers' perceptions of model functions by using Nia and de Vries' (2017) framework of identified 


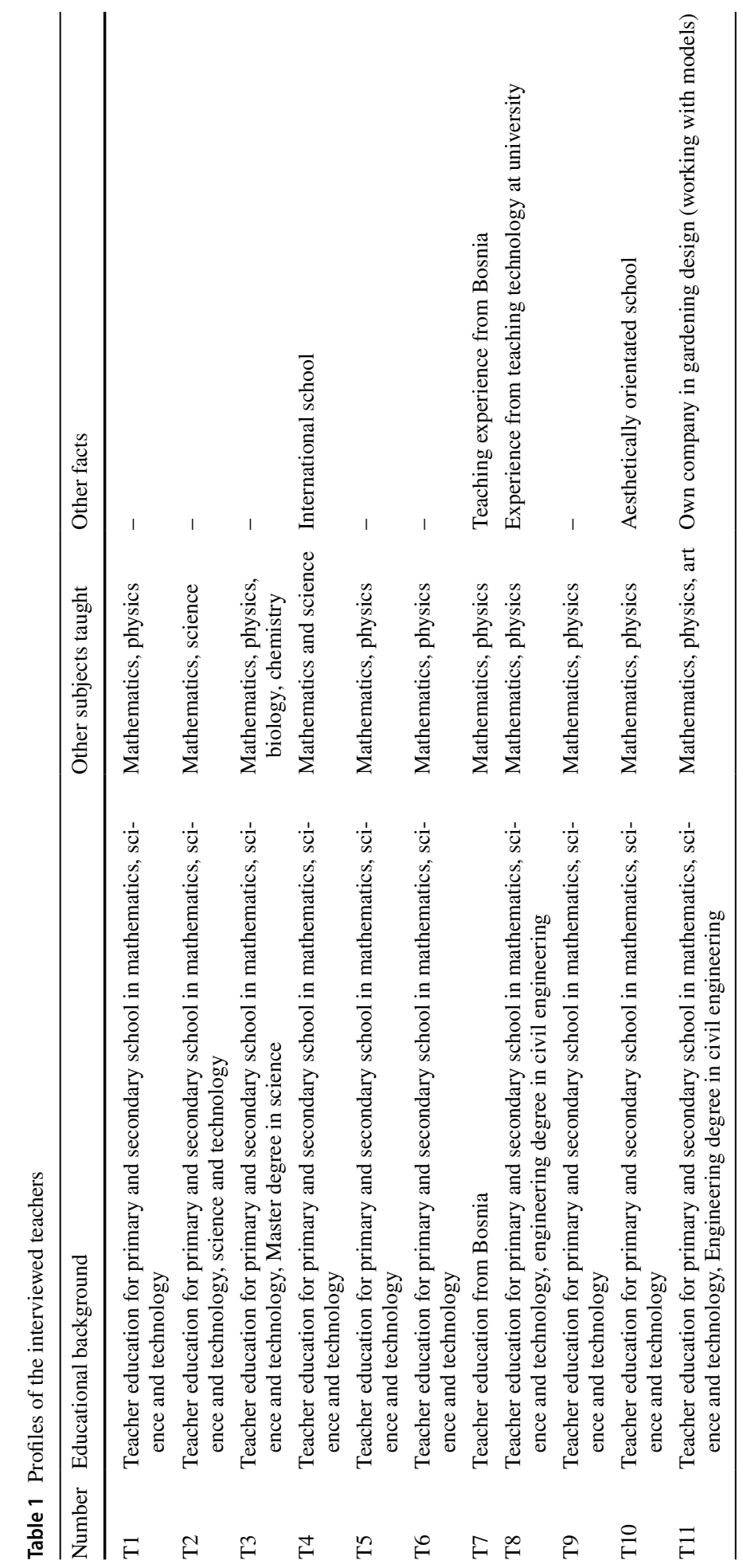


functions of models with which students must become acquainted in order to understand the meaning of models in technology. The functions identified in their study were; demonstrating, designing, testing and evaluating, prototyping, simulating, problem solving, communicating and finally learning. We returned to the transcripts, and read them several times again, in search of statements where teachers talked about using models for a purpose (as a function). Several statements were clustered and named. To better understand the statements about functions, the context was also identified. In total, 10 different model functions were found in two different contexts.

\section{Validity and reliability}

Lincoln and Guba (1985) describe a division of how the truth value of research results of an interpretive nature can be discussed on the basis of trustworthiness, credibility and transferability. Credibility concerns the researcher's knowledge of the area being researched - in the present study, technology teachers' perceptions of model functions. It is a question of the researcher's pre-understanding as a quality requirement, that what he/she sees, hears, interprets and writes is relevant to the purpose of the study (Elo et.al 2014).

In a qualitative study, reliability is built up by the fact that the selection of informants is considered suitable and relevant to be able to answer the research questions. The informants are experienced technology teachers from different parts of Sweden (see Table 1). The interview questions in the studies are of a semi-structured nature, which means that they consist of some specific and recurring questions as well as follow-up questions that are linked to how the interviewees answer.

Communicative credibility is about presenting results and conclusions in such a way that it can be reviewed and reliability can be assessed by the research community. By presenting extracts from transcripts, we have made it easier for other researchers to assess the interpretations that have been made and capture the meaning of perceptions that are presented as categories. By describing analysis processes of studies, there is also an opportunity to form an opinion on whether the result has emerged in a reliable manner, and an opportunity to conduct a similar study is opened.

This study was performed according to ethical considerations in the text "Good research practice" formulated by the Swedish Research Council (2017). The interviewed teachers were fully aware of intentions with the research and the usage of material, and could at any time retreat from the study.

\section{Results}

The first step of the content analysis resulted in a description of teachers' understanding of models as tools for communication or as tools for the design process. These two themes of understanding were interesting, but did not provide enough information about teachers' perceptions; therefore we focus on the result from the second step of the analysis, the directed analysis. The outcome of the directed content analysis resulted in two different contexts, in which 10 different model functions were identified (see Table 2). The two contexts are descriptions of technology teaching situations: 


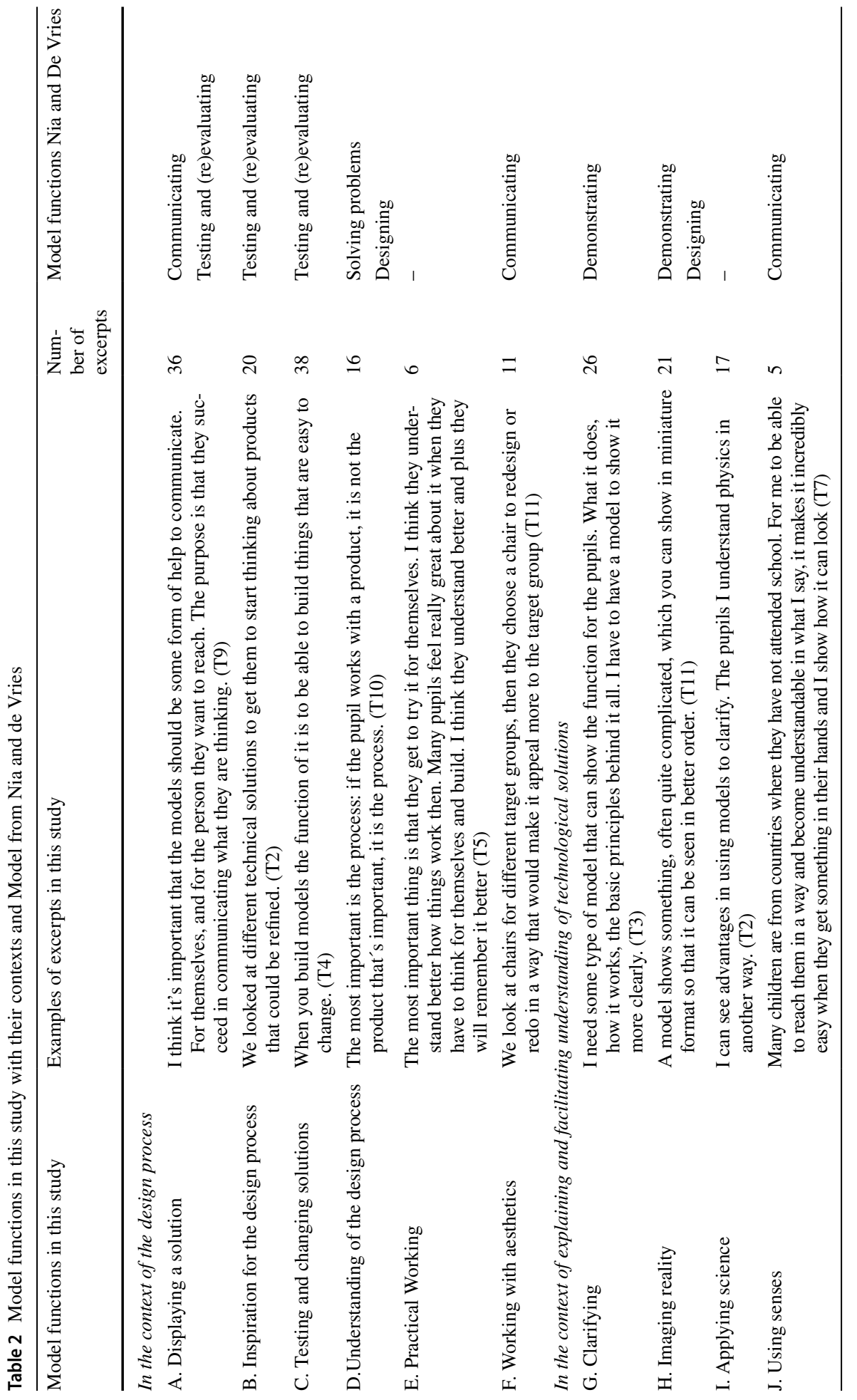


- The design process - where the focus is on solving technological problems using the design process: identifying the problem/needs, investigating conditions, proposing solutions, designing and testing (Skolverket 2018)

- Explaining and facilitating understanding of technological solutions-teachers use models to explain and clarify specific situations or functions for pupils. Teachers also use models to concretise technological solutions, giving pupils the opportunity to investigate the solutions.

Within the two contexts there are six functions that relate to the design process $(A$. displaying solution; $B$. Inspiration for design process; $C$. Testing and changing solutions; $D$. Understanding of the design process; E. Practical working; F. Working with aesthetics) and four functions that relate to the context explaining and facilitating understanding of technological solutions (G. Clarifying; H. Imaging reality; I. Applying science; and J. Using senses) (Table 2).

In the following section we describe the model functions, in which context they occur, and exemplify them with excerpts-we also connect our functions to Nia and de Vries (2017).

\section{The design process}

A. In connection to the context design process, the teacher's perception of model functions supports pupils' options for displaying solutions. Pupils present their cognitive models of a technological solution as a representation, for example as physical model, digital model and/or sketch. With these expressed models, pupils describe and communicate their ideas. We interpret that teachers do this to open opportunities for pupils to learn and to evaluate aspects such as material, functionality and fitness for purpose of technological solutions; but also as an opportunity for the pupils to learn how to use models as a way to communicate, using technological language. This is in line with Nia and de Vries' (2017) model function Communicating, a way to express ideas and design proposals, and Testing and (re)evaluating ideas, solutions, designs, and processes, "to determine how well they meet the identified requirements and targets. Ensure the quality, efficiency, strength of the designed model." (p. 634).

Models are a way for us to speak in common language, so that we understand each other. It is not so easy to interpret what a person is trying to express from his head. But when we start working with models, we can cooperate, understand and approach something that we have in common. (T11)

B. Another way in which teachers in this study perceive the function of models in technology education is as inspiration for the design process. When pupils are exposed to a model that represents a technological solution, their cognitive models are challenged and new ways of understanding are opened. The aim is to create opportunities for pupils to learn to evaluate aspects such as material, functionality and fitness for purpose of technological solutions. This model function is connected to Nia and de Vries' (2017) Testing and (re)evaluating, to determine how well they meet the identified requirements and targets.

Then they were commissioned to improve an existing product for the company and build a model of it. Thus, they draw and build a model of it and present their 
thoughts for the company's management. That was among the best we have done.

C. In the design process testing and changing solutions are central, and the function of models plays a specific role in this process when testing and retesting different possible technological solutions, with the aim for pupils to learn to optimise a technological solution in relation to the purpose and predefined conditions. Also, this model function could be understood as the model function Testing and (re)evaluating described by Nia and de Vries (2017), since it is about testing and evaluating ideas, solutions, designs, and processes, to determine how well they meet the identified requirements and targets.

We have worked a bit with disability-aids of various kinds. In fact, the models have been important for testing ideas, if it really is an idea that works at all. They try to visualise their thought processes by using a model. (T11)

D. The teachers use models in technology education to support pupils' understanding of the design process. We interpret this as learning a specific way of working when solving technological problems where models are included in different parts of the process. Pupils need to understand and learn the function of models, for example as prototypes, sketches and drawings, in the design process. This model function is related to two of Nia and de Vries' (2017) model functions, solving problems and the designing of model proposals by sketching and determining the proper features and scales of needed models.

It is not just someone who hatches an idea of a product, but it is a fairly long process before you arrive with a finished product. But with the advancement that technology has today, it is probably very important that we include understanding of this process in the school's work. (T1)

E. The function of working practically in technology is perceived as important by some teachers. The practical work itself, when using models, is perceived by the teachers as a counterweight to more theoretical contents in school. The work with models and modelling enables pupils that have problems in understanding theoretical knowledge to show their practical capabilities. When working practically, teachers open opportunities for pupils to show their knowledge about constructing models fit for purpose. We interpret that this model function does not have a strong connection to any of Nia and de Vries' (2017) model functions.

One purpose is to use models to make the education more practical. That it should not just be theory, but that we can practically create and do something. (T6)

F. The last function of this context is Working with aesthetics, where the teachers perceive the use of models as a way of motivating the pupils to think about and develop knowledge about the aesthetics when designing a model for a specific aim. This function is indirectly related to several of the other functions, since the aesthetics depends on the construction, but this function is more about teaching the pupils to make a product that is appealing to the user, not only fit for the purpose. In relation to Nia and de Vries' (2017) model functions we connect this to communicating ideas and solutions to others through various forms of modelling.

We work with building small cars, but I focus on both getting the car to roll and that it looks nice. I try to combine aesthetics and function, a little bit of both. (T7) 


\section{Explain and facilitate understanding of technological solutions}

Of course, technology education fundamentally is about explaining and understanding, which leads to all functions being related to explaining and understanding. However, we see great value in defining the context of explaining and understanding as a context of its own since we interpret it as the teachers perceiving this as something else than the design process. In this context we define four different functions of models depending on the purpose of using them.

G. The most common function of models, in the context of explaining and facilitating understanding of technological solutions, is to clarify technological solutions and functions. This is used by the teachers to display and explain technological solutions, or as a chance for pupils to construct models of their own in order to better understand a solution. According to the teachers, the model can be simplified or shown/built in different scales, in order to see and understand details or functions. The model could also display a technological system or a part of a system in order to clarify the function or structure of the system as a technological solution. The aim with using models to clarify is to make pupils aware of details and functions of technological solutions; when doing this, pupils' cognitive models are challenged by expressed models. The model function clarify has a connection to what Nia and de Vries (2017) call demonstrating, which is described as a model function that is used to demonstrate (or represent) the provided design concepts, to try out the visions and ideas, or to show how different technological devices work or are used.

When you build models, the function is that you can more easily see how things work. (T4)

H. One way in which the teachers perceive the function of models is imaging reality. The teachers mention building scale models of real things such as houses, bridges and other technical solutions or a drawing that shows an image of the reality. Our interpretation is that the teachers do this in order to make the pupils notice certain solutions and structures of expressed models so that pupils' cognitive models are challenged. Two of Nia and de Vries' (2017) model functions are related to our identified model function. One is demonstrating: models are used to represent the provided design concepts and to show how different technological devices work or are used. The other is designing: models are used for design proposals by sketching and determining the proper features and scales of needed models.

We look at powerful electromagnets on lifting cranes on the scrap yard, and I myself make a model of a small battery and a copper wire that is wound into it; and there we have the model to show the functioning of the participating components, what they do, what purpose they have. Then I use this model to show the different functions. (T3)

I. Several interviewed teachers (nine of the eleven) perceive the function of models in technology as a way to apply science. The teachers describe that they use models to make phenomena in the subject physics understandable, which we interpret to mean that they use models not as a way of understanding and learning technology, but as a support to learn and understand physics. The aim is to use the expressed models of a phenomenon to challenge pupils' cognitive models of those phenomena. 
This model function is not related to Nia and de Vries' (2017) model functions, that describe what pupils need to understand of models in technology.

For example, if we are doing electromagnetism in physics and acoustics, then the pupils will practise the physics we have read. So they get a view: but how does a speaker really work? (T2)

J. Teachers perceive that by using a model, pupils with insufficient language have the opportunity to investigate and understand the technological solution using several senses at the same time. When pupils do not have a language to communicate with, the use of senses becomes more important for understanding properties of technological solutions, and in that way it challenges their cognitive models. We interpret that when teachers explain the function, structure and material in an expressed model by asking pupils to use their eyes, ears and hands, they bridge the problems caused by insufficient language. We interpret this model function to Nia and de Vries (2017) communicating using senses to communicate ideas and design proposals with models.

Most of the time it is about me making an evaluation of what I can explain. Do the students understand it just by listening or just by me drawing on the blackboard? Or do I need them to be able to move it themselves? It varies between groups and pupils; some have a need for being able to feel and look at a physical model. (T3)

When using Nia and de Vries (2017) to guide us in the directed content analysis, the results indicate that the model functions identified in our study are connected to some of the model functions in Nia and de Vries' study, but not all. The model functions that we in our study relate to are communicating, testing and (re)evaluating, problem solving, designing and demonstrating. The model functions prototyping, simulating and learning are not identified in the teachers' descriptions of the use of models. We find the function named learning by Nia and de Vries (2017) not as a separate function but an inclusive function in the other functions; for example, when a student communicates the reason for doing as to understand and learn about something, technology in the design process, not only communicating for its own sake. In relation to this, it is important to remember the different focus in our studies, where Nia and de Vries investigate what students need to understand about models in technology, and we investigate teachers' understanding of models in technology education. There are thus evident connections between the investigations, since the teachers describe the use of models in education as an aim to make pupils understand technology. Two of our functions could not be connected to Nia and de Vries functions. One function was more related to science, Applying science, and the other was related to the hands-on work, Practical working.

To better understand the dissemination of the outcome we present the model functions in relation to each teacher (Table 3). In this way we can examine the teacher profile, Teacher 1, T1-Teacher 11, T11, (see Table 1), and interpret whether or not the profile influences their perception of model functions in technology education.

From Table 3 it becomes clear that all teachers have excerpts in both contexts, but there are some that have a stronger connection to the design process, for example $\mathrm{T} 1$ and $\mathrm{T} 11$, and others that have a stronger connection to explaining and facilitating understanding of technological solutions, for example T3 and T9. Looking closer at the teacher profiles of T11 and T3, we interpret that their background and the subjects that they teach affect their perceptions of model functions. If we look at these two teachers' educational background, both are Grade 4-9 teachers in mathematics and science, T3 has a master degree in science 
while T11 has an engineering degree. Except for technology, T3 teaches all science subjects (physics, biology and chemistry) as well as mathematics, while T11 teaches art and physics, again excepting technology. During the interview T3 described a lack of knowledge about models and an uncertainty about using them in technology. T3 said a great deal about models in science and how theories from science could be explained by using models in technology, thus to apply science. On the other hand, T11 had a clear picture of models and modelling and used them frequently in all subjects. T11 mentions the advantages of working and cooperating between the subjects art and technology, when it comes to models and modelling. We interpret that T11 is influenced by an engineering background and the understanding of models and modelling as part of the design process, while T3 is more influenced by a scientific background, understanding models and modelling as a way to explain and understand phenomena and theories.

Looking at two other teachers, T2 and T6, at first sight they look very different, as T2 is the only teacher with excerpts in all the model functions, while T6 has the least number of excerpts. However, there are also similarities - both teachers have about the same percentage of excerpts in the two contexts, design process and explaining and facilitating understanding of technological solutions, and they are both Grade 4-9 teachers in science and technology, are the same age and have been working for more than 10 years. In the interview, T2, who is more secure about using models, has a focus on the model function of applying science, while T6 is insecure about using models, and has a focus on displaying solutions. We interpret that T6 finds that an important function of models in technology is to be able to work practically in an increasingly theoretical school, while T2 perceives that the function of models is to illustrate and clarify physics by working practically. None of them talks about how models are an important part of developing a product during the design process. However, we interpret that $\mathrm{T} 2$ has a connection to how aesthetics could be used in the design process to adapt products for a special user.

\section{Discussion}

Technology teachers perceive the use of model functions in teaching as connected to the design process and/or to the understanding of technological solutions. These two contexts indicate that models are used to develop practical as well as theoretical knowledge. Model functions are understood as parts of the design process which relate to technology/engineering knowledge and a scientific, descriptive way of understanding models. Engineers use models to make decisions when solving problems (Kroes 2009), which is closely connected to the descriptions of how and why technology teachers use models in the design process when teaching technology. Models are used in science to describe and explain phenomena, to make abstract entities visible and to provide descriptions and/or simplifications (France et.al 2011), which in turn is related to the identified context where teachers use models to explain and clarify specific technological situations or functions when teaching technology.

The relation between our study and Nia and de Vries (2017) indicates that in the context of the design process, the functions communicating and testing and (re)evaluating are recurring in our study. Two other functions, designing and problem solving, are only found in one of our model function descriptions, which could be understood as teachers' lack of knowledge about what pupils need to understand. In the other context, explaining and facilitating understanding of technological solutions, the functions demonstrating, communicating and designing are present. Overall, we interpret that the teachers' focus is on using 
Table 3 Number of excerpts from each teacher (T1-T11) connected to the model functions. (MAXQDA 2018)

\begin{tabular}{|c|c|c|c|c|c|c|c|c|c|c|c|c|c|}
\hline \multicolumn{2}{|c|}{ Code System } & $\mathrm{T} 1$ & T2 & T3 & T4 & T5 & T6 & $\mathrm{T7}$ & T8 & T9 & $\mathrm{T} 10$ & T11 & SUM \\
\hline \multirow[t]{7}{*}{$\nabla \odot$} & $\bullet$ Design Process & & & & & & & & & & & & 0 \\
\hline & $C_{\bullet}$ A. Displaying a solution & 8 & 2 & 2 & 2 & 1 & 4 & 1 & 3 & 6 & 1 & 6 & 36 \\
\hline & B. Inspiration for the designprocess & 3 & 3 & & 4 & 3 & & 1 & 1 & & 4 & 5 & 24 \\
\hline & C. $\mathrm{c}$. Testing and changeing solutions & 3 & 3 & 1 & 8 & 3 & 2 & 2 & 3 & 6 & 2 & 5 & 38 \\
\hline & $\bullet$ D. Understanding of the design pro & 4 & 1 & 2 & 1 & & & 1 & & 1 & 6 & & 16 \\
\hline & E. Practical workning & & 1 & & & 1 & 2 & & & & & 2 & 6 \\
\hline & $\ominus_{\bullet}$ F. Working with aesthetics & 3 & 2 & & & 2 & & 2 & 1 & & & 1 & 11 \\
\hline \multirow[t]{6}{*}{$\nabla$} & $\odot$ Explaining and facilitating understandin & & & & & & & & & & & & 0 \\
\hline & $e_{0}$ H. Clarifying & 5 & 1 & 5 & 5 & 1 & 2 & 1 & 1 & 2 & 1 & 2 & 26 \\
\hline & $\bullet$ I. Imaging reality & & 2 & 2 & 5 & 2 & 2 & 1 & 1 & 5 & 1 & & 21 \\
\hline & $\bullet_{\bullet}$ J. Applying science & & 5 & 1 & 2 & 5 & & & & 3 & 1 & & 17 \\
\hline & @ K. Using senses & & 1 & 1 & & & & 2 & & 1 & & & 5 \\
\hline & $\sum$ sum & 26 & 21 & 14 & 27 & 18 & 12 & 11 & 10 & 24 & 16 & 21 & 200 \\
\hline
\end{tabular}

model functions as representations (expressed models). This empirical study contributes with important knowledge about teachers' perspectives on the use of model functions in technology teaching, which complements the study of policy documents by Nia and de Vries (2017).

In all STEM subject areas, the use of models and modelling is included to support understanding. As mentioned by Hallström and Schönborn (2019) STEM subject areas represent different knowledge, which implies that model functions in technology are something else than model functions in science. The teachers in this study often perceive model functions in science and technology as the same. This could be both an advantage (they connect the subjects in a STEM-like way) and a disadvantage (they do not know the difference between the subjects). Technology, also engineering, is normative and science is descriptive (France et.al 2011); signs of normativity are found in some of the descriptions of model functions, for example in Category $C$. Testing and changing solutions, but there are also signs of descriptivity in several of the model functions in understanding of technological solutions. We interpret that this is related to the profile of the teachers where all teachers in the study teach technology together with science, which influences their understanding of model functions in technology.

In relation to Buckley (2000), teachers in this study focus on challenging pupils' cognitive models by using representations in order to influence and change their cognitive model. Thus, the teachers in our study do not use models to solve problems, evaluate or modify models, which we interpret to signify that they have more of a connection to science than technology/engineering. We find the function applying science in our study as a further evidence of the teachers' close connections to science rather than technology/ engineering. The fact that some of the teachers describe practical working as a model function could be related to the Swedish technology curriculum and education, that has a strong tradition connected to slöjd (handcraft) where practical work is emphasised.

\section{Conclusion}

The conclusion of this study is that it is important that technology teachers who also teach science are aware of the different ways of using models in these subjects. We especially find it important to address the use of models in technological design process activities, 
where the model functions are used for developing the solution in a prescriptive way. This could be understood as meaning that Swedish technology teachers would benefit from developing their knowledge about the design process, where models are used as representations that can be modified and developed to help the engineer in the decision-making process.

This study contributes with knowledge about technology teachers' perceptions of model functions in technology education; however, the uncertainty of the connections between technology, engineering and science implies the necessity for further research about the use and purpose with models in technology education, as well as the impact of teachers' backgrounds and knowledge base for teaching about models in technology.

Funding Open access funding provided by Linnaeus University.

Open Access This article is licensed under a Creative Commons Attribution 4.0 International License, which permits use, sharing, adaptation, distribution and reproduction in any medium or format, as long as you give appropriate credit to the original author(s) and the source, provide a link to the Creative Commons licence, and indicate if changes were made. The images or other third party material in this article are included in the article's Creative Commons licence, unless indicated otherwise in a credit line to the material. If material is not included in the article's Creative Commons licence and your intended use is not permitted by statutory regulation or exceeds the permitted use, you will need to obtain permission directly from the copyright holder. To view a copy of this licence, visit http://creativecommons.org/licenses/by/4.0/.

\section{References}

Allwood, J. (1989). Modellering som analys och specificeringsmetod. MILINF 90, Eskilstuna 1989, Institutionen för Lingvistik. University of Gothenburg.https://gup-server.ub.gu.se/v1/asset_data/121896

Buckley, B. C. (2000). Interactive multimedia and model-based learning in biology. International Journal of Science Education, 22(9), 895-935. https://doi.org/10.1080/095006900416848.

Citrohn, B. (2018). Modeller i teknikkursplaner: En jämförelse mellan några olika länder (Dissertation). https://urn.kb.se/resolve?urn=urn:nbn:se:liu:diva-162257

De Vries, M. J. (2005). Teaching about Technology An introduction to the Philosophy of technology for non philosophers. Dordrecht: Springer-Verlag New York Inc.

Elo, S., Kääriäinen, M., Kanste, O., Pölkki, T., Utriainen, K., \& Kyngäs, H. (2014). Qualitative content analysis: A focus on trustworthiness. SAGE Open. https://doi.org/10.1177/2158244014522633.

France, B., \& Compton, V. J. (2007). Towards a new technological literacy: Curriculum development with a difference. Curriculum Matters, 3, 158-175.

France, B., Compton, V. J., \& Gilbert, J. K. (2011). Understanding modelling in technology and science: The potential of stories from the field. International Journal of Technology and Design Education, 21, 381-394. https://doi.org/10.1007/s10798-010-9126-4.

Gilbert, J. K. (2004). Models and modelling: Routes to more authentic science education. International Journal of Science and Mathematics Education, 2, 115-130. https://doi.org/10.1007/s1076 3-004-3186-4.

Grosslight, L., Unger, C., Jay, E., \& Smith, C. L. (1991). Understanding models and their use in science: Conceptions of middle and high school students and experts. Journal of Research in Science Teaching, 28(8), 799-822.

Hallström, J., \& Schönborn, K. J. (2019). Models and modelling for authentic STEM education: Reinforcing the argument. International Journal of STEM Education., 6(22), 1-10. https://doi.org/10.1186/s4059 4-019-0178-z.

Heinz, S. (2011). Mathematical modeling. Berlin Heidelberg: Springer Science and business media.

Hsieh, H. F., \& Shannon, S. E. (2005). Three approaches to qualitative content analysis. Qualitative Health Research, 15(9), 1277-1288. https://doi.org/10.1177/1049732305276687.

Kroes, P. (2009). (2009). Foundational issues of engineering design. In A. Meijers (Ed.), Philosophy of technology and engineering sciences (pp. 513-541). Amsterdam: Elsevier.

Leatherdale, W. H. (1974). The role of analogy, model and metaphor in science. Amsterdam: Elsevier. 
Lin, J. W. (2014). Elementary school teachers' knowledge of model functions and modeling processes: A comparison of science and non-science majors. International Journal of Science and Mathematics Education., 12, 1197-1220. https://doi.org/10.1007/s10763-013-9446-4.

Lincoln, S. Y., \& Guba, E. G. (1985). Naturalistic inquiry. Thousand Oaks: Sage.

Marion, G., \& Lawson, D. T. (2008). An introduction to mathematical modelling given 2008 by daniel lawson and glenn marion. Scotland: Bioinformatics and Statistics.

Mitcham, C. (1994). Thinking through technology - the path between engineering and philosophy. Chicago: University of Chicago Press.

Nia, M.G. and de Vries, M.J. (2017). Models as artefacts of a dual nature: a philosophical contribution to teaching about models designed and used in engineering practice. International Journal of Technology and design education. 27. p. 627-653.https://link.springer.com/content/pdf/10.1007\%2Fs10798-0169364-1.pdf

Roberts, P., Archer, L. B., and Baynes, K. (1992). Modelling: the language of designing design: Occasional paper No 1. Loughborough: Loughborough University.

Rossouw, A., Hacker, M., \& de Vries, M. J. (2011). Concepts and contexts in engineering and technology education: An international and interdisciplinary Delphi study. International Journal of Technology and Design Education., 21, 409-424.

Simon, H. A. (1996). The Sciences of the artificial. London: MIT-press.

Skolverket, (2018). Curriculum for the compulsory school, preschool class and school-age education Revised 2018. https://www.skolverket.se/getFile?file=3984

Swedish Research council (2017). Good research practice.https://www.vr.se/download/18.5639980c16 2791bbfe697882/1555334908942/Good-Research-Practice_VR_2017.pdf

VERBI Software (2019) MAXQDA 2018.

Wells, M., Hestenes, D., \& Swackhamer, G. (1995). A modeling method for high school physics instruction. American Journal of Physics, 63(7), 606-619.

Publisher's Note Springer Nature remains neutral with regard to jurisdictional claims in published maps and institutional affiliations. 